Cite this: CrystEngComm, 2013, 15, 2640

Received 10th December 2012, Accepted 18th January 2013

DOI: 10.1039/c3ce26997c

www.rsc.org/crystengcomm

\title{
Twinning and epitaxial growth of taaffeite-type modulated structures in $\mathrm{BeO}$-doped $\mathrm{MgAl}_{2} \mathrm{O}_{4}{ }^{\dagger}$
}

\begin{abstract}
Sandra Drev, Aleksander Rečnik and Nina Daneu
A recent study of (111) twins in $\mathrm{MgAl}_{2} \mathrm{O}_{4}$ spinel crystals from Mogok (Burma) implied that twinning could be triggered by the presence of Be during crystal growth. Here we demonstrate that twinning in spinel is in fact chemically induced and is not a consequence of an accidental attachment of crystals. The growth conditions were reproduced in a tube furnace at $1200{ }^{\circ} \mathrm{C}$ by liquid-phase assisted reaction of $\mathrm{Al}_{2} \mathrm{O}_{3}$ and $\mathrm{MgO}$ with the addition of $\mathrm{BeO}$, while $\mathrm{PbF}_{2}$ was used as melt-forming agent. $\mathrm{BeO}$ does not only cause abundant $\{111\}$ twinning of spinel, but also complex topotaxial overgrowths of $\mathrm{BeMg}_{3} \mathrm{Al}_{8} \mathrm{O}_{16}$ taaffeite when the concentration of BeO exceeds $12.5 \mathrm{~mol} \%$. A HRTEM study of the spinel-taaffeite interface confirmed the following epitaxial relationship: [1 10$] \cdot\{111\}_{s p} \|[11 \overline{2} 0] \cdot\{0001\}_{\text {taf. }}$ The basic structural unit, observed on (111) twin boundary in spinel (i.e. $\mathrm{Be}^{2+}$ replacing for $\mathrm{Mg}^{2+}$ on the interfacial tetrahedral interstices), is identical to hexagonal close-packed (hcp) sequences observed in ternary taaffeite compounds, suggesting that twinning is probably a preparatory stage of polytype formation. The formation $\{111\}$ twins in spinel is explained in the context of twin-induced exaggerated grain growth mechanism. This phenomenon can be exploited for the production of spinel crystals with complex morphologies.
\end{abstract}

\section{Introduction}

Magnesium aluminate $\mathrm{MgAl}_{2} \mathrm{O}_{4}$ (spinel) has many technological applications due to its outstanding thermal, mechanical and optical properties. In order to obtain the desired physical properties of spinel ceramics one of the main objectives is efficient control of microstructure development during processing. ${ }^{1}$ Recently, we have shown, that grain growth in ceramics can be successfully engineered by introduction of chemically induced polytypic faults in crystal grains during growth. ${ }^{2}$ Planar faults, such as twin, inversion and antiphase boundaries, play a key role in microstructure development. They produce an abrupt structural and chemical anisotropy, which is reflected in exaggerated growth. This phenomenon can be exploited for microstructural engineering and tailoring physical properties of functional materials in virtually any system that is prone to the formation of such polytypic faults. ${ }^{3}$

In the study of twin boundaries in natural spinel crystals from Burma, Daneu et al. ${ }^{4}$ proposed that twinning in $\mathrm{MgAl}_{2} \mathrm{O}_{4}$ is triggered during crystal growth by incorporation of beryllium on the twin boundary. Crystallographically, a twin boundary in spinel is produced by $180^{\circ}$ rotation around the [111] axis, ${ }^{5}$ resulting in the local hep stacking across the

Department for Nanostructured Materials, Jožef Stefan Institute, Jamova cesta 39, SI1000 Ljubljana, Slovenia

† Electronic supplementary information (ESI) available. CCDC 915415, 915416, 915424 and 915425 . For ESI and crystallographic data in CIF or other electronic format see DOI: $10.1039 / \mathrm{c} 3 \mathrm{ce} 26997 \mathrm{c}$ interface, where the tetrahedral sites are occupied by $\mathrm{Be}^{2+}$ instead of $\mathrm{Mg}^{2+}$. In addition to indirect evidences for Be provided by transmission electron microscopy (TEM) methods and Pauling's principle of electroneutrality the authors further supported their hypothesis by the existence of close structural relationship between spinel $\left(\mathrm{MgAl}_{2} \mathrm{O}_{4}\right)^{6}$ and chrysoberyl $\left(\mathrm{BeAl}_{2} \mathrm{O}_{4}\right),{ }^{7}$ and the existence of intermediate polytypic, taaffeite-type $\left(\mathrm{Be}_{x} \mathrm{Mg}_{y} \mathrm{Al}_{2(x+y)} \mathrm{O}_{4(x+y)}\right)$ series. $^{8-18}$

The common feature that can be observed on twin boundaries, taaffeite compounds as well as in the chrysoberyl structure is the presence of $\mathrm{Be}^{2+}$ on the tetrahedral sites next to the hcp stacking of the oxygen sublattice. In the spinel structure, oxygen-sublattice is repeated in cubic, ccp stacking, along all four $<111>$-axes, whereas in the chrysoberyl structure, the oxygen sublattice is repeated in hcp stacking along the $<0001>$-axis. Similar structural features are observed in natural and synthetic taaffeite-type compounds with different periodicities of cep and hcp sequences; i.e. $\mathrm{BeMgAl}_{4} \mathrm{O}_{8},{ }^{8-10} \quad \mathrm{Be}_{3} \mathrm{Mg}_{5} \mathrm{Al}_{16} \mathrm{O}_{32},{ }^{11} \quad \mathrm{BeMg}_{2} \mathrm{Al}_{6} \mathrm{O}_{12}{ }^{12-18}$ and $\mathrm{BeMg}_{3} \mathrm{Al}_{8} \mathrm{O}_{16} \cdot{ }^{14-18}$ The existence of similar structural elements implies that Be-induced twinning in spinel is nothing but a preparatory stage of polytypic phase transformation in the $\mathrm{MgAl}_{2} \mathrm{O}_{4}-\mathrm{BeAl}_{2} \mathrm{O}_{4}$ system. ${ }^{4}$ Using a flux method, Tabata and Isshi $^{19}$ succeeded to grow twinned spinel crystals with the addition of $\mathrm{BeAl}_{2} \mathrm{O}_{4}$ and suggested that the local structure of twin boundaries could be related to chrysoberyl or even olivine $\left(\mathrm{Mg}_{2} \mathrm{SiO}_{4}\right)$, because both minerals coexist with spinel in natural environments. 
Table 1 Sample compositions for studies of phase formation in the $\mathrm{MgO}-\mathrm{Al}_{2} \mathrm{O}_{3}-\mathrm{BeO}$ system. Taaffeite phase compositions were prepared according to the stoichiometry of reported compounds ${ }^{16}$

\begin{tabular}{|c|c|c|c|c|c|}
\hline Sample & Targeted phase & $\mathrm{MgO}(\mathrm{mol} \%)$ & $\mathrm{Al}_{2} \mathrm{O}_{3}(\mathrm{~mol} \%)$ & $\mathrm{BeO}(\mathrm{mol} \%)$ & $\mathrm{PbF}_{2}(\mathrm{~mol} \%)$ \\
\hline Sp & $\mathrm{MgAl}_{2} \mathrm{O}_{4}$ & 40 & 40 & & 20 \\
\hline T3 & $\mathrm{BeMg}_{3} \mathrm{Al}_{8} \mathrm{O}_{16}$ & 30 & 40 & 10 & 20 \\
\hline T1 & $\mathrm{BeMgAl}_{4} \mathrm{O}_{8}$ & 20 & 40 & 20 & 20 \\
\hline $\mathrm{Ch}$ & $\mathrm{BeAl}_{2} \mathrm{O}_{4}$ & & 40 & 40 & 20 \\
\hline
\end{tabular}

Until now, the influence of BeO-addition on twin formation and microstructure development of synthetic spinel-based ceramics has not been studied yet. The main objective of our work was to confirm if $\{111\}$ twinning in $\mathrm{MgAl}_{2} \mathrm{O}_{4}$ can indeed be triggered by the addition of $\mathrm{BeO}$, as suggested previously, ${ }^{4,19}$ and to what extent this influences the growth and morphology of $\mathrm{MgAl}_{2} \mathrm{O}_{4}$ crystals. In addition to twinning we also investigated the formation of taaffeite-type compounds in the $\mathrm{MgO}-\mathrm{Al}_{2} \mathrm{O}_{3}-\mathrm{BeO}$ system.

\section{Experimental work}

\section{Sample preparation}

For our study of phase formation in the $\mathrm{MgO}-\mathrm{Al}_{2} \mathrm{O}_{3}-\mathrm{BeO}$ system, we prepared samples with the compositions listed in Table 1, following a standard mixed-oxide technique. Reagent grade powders of $\mathrm{MgO}$ (99\%, Alfa Aesar, C23W021), $\mathrm{Al}_{2} \mathrm{O}_{3}$ (99\%, Alfa Aesar, F28X120), BeO (99\%, Alfa Aesar, F17T009) and $\mathrm{PbF}_{2}$ (99\%, Alfa Aesar, 824R038), were mixed in appropriate ratios and homogenized in absolute ethanol. $\mathrm{PbF}_{2}$ was used as a liquid forming additive in order to enhance the diffusion processes, while its relatively large amount (20\%) was used to assist unconstrained crystal growth and semiidiomorphic development of crystal grains, which is convenient for simple identification of crystal morphology. Another set of samples was prepared to study the influence of BeOdoping on twinning in $\mathrm{MgAl}_{2} \mathrm{O}_{4} \cdot{ }^{4,19}$ For this purpose, the samples with $\mathrm{MgO}-\mathrm{Al}_{2} \mathrm{O}_{3}$ ratio of $1: 1$, and different additions of $\mathrm{BeO}(0.1,1.0$ and $10.0 \mathrm{~mol} \%)$ were prepared. Homogenized powders were pressed into pellets under a pressure of $200 \mathrm{MPa}$ and sintered for $16 \mathrm{~h}$ at $1200{ }^{\circ} \mathrm{C}$ in air with heating and cooling rates of $10 \mathrm{~K} \mathrm{~min}^{-1}$.

\section{Characterization methods}

Phase composition of the samples was determined by X-ray powder diffractometry (XRD; PW1710, Philips, Germany) using Ni-filtered $\mathrm{Cu} \mathrm{K} \alpha$ radiation in the range $2 \theta=10^{\circ}-60^{\circ}$ with a step of $0.04^{\circ}$ and recording time of $1 \mathrm{~s}$ per step. Microstructural investigations were performed on a scanning electron microscope (SEM; JSM-5800, Jeol, Japan) and equipped with an energy dispersive X-ray spectrometer (EDS; Link ISIS 300, Oxford Instruments, England). For SEM studies the sintered pellets were coated with amorphous carbon to improve electron conductivity. The surfaces of the samples covered with freely developed crystals were examined at an accelerating voltage of $10 \mathrm{kV}$ to avoid charging effects on uneven surfaces. EDS analyses were performed on polished cross-sections of the samples at and accelerating voltage of 20 $\mathrm{kV}$ and the measurements were quantified using the internal standards. Detailed structural investigations of the samples were performed by transmission electron microscopy (TEM) using a $200 \mathrm{kV}$ microscope (TEM; JEM-2100, Jeol, Japan). For TEM investigations the samples were cut into $3 \mathrm{~mm}$ discs, mechanically thinned to $100 \mu \mathrm{m}$, and dimpled to $20 \mu \mathrm{m}$ in the disc center. Transmissive regions at the specimen center were obtained by ion milling (PIPS, Precision Ion Polishing System, Gatan Inc., USA), utilizing $4 \mathrm{kV} \mathrm{Ar}^{+}$ions at an incidence angle of $8^{\circ}$, until perforation.

\section{Results and discussion}

\section{Phase formation in the $\mathrm{MgO}-\mathrm{Al}_{2} \mathrm{O}_{3}-\mathrm{BeO}$ system}

XRD analyses of the samples with compositions listed in Table 1, are shown in Fig. 1. In the sample, where $\mathrm{MgO}$ and $\mathrm{Al}_{2} \mathrm{O}_{3}$ were mixed in stoichiometric ratio for $\mathrm{MgAl}_{2} \mathrm{O}_{4}$ (sample

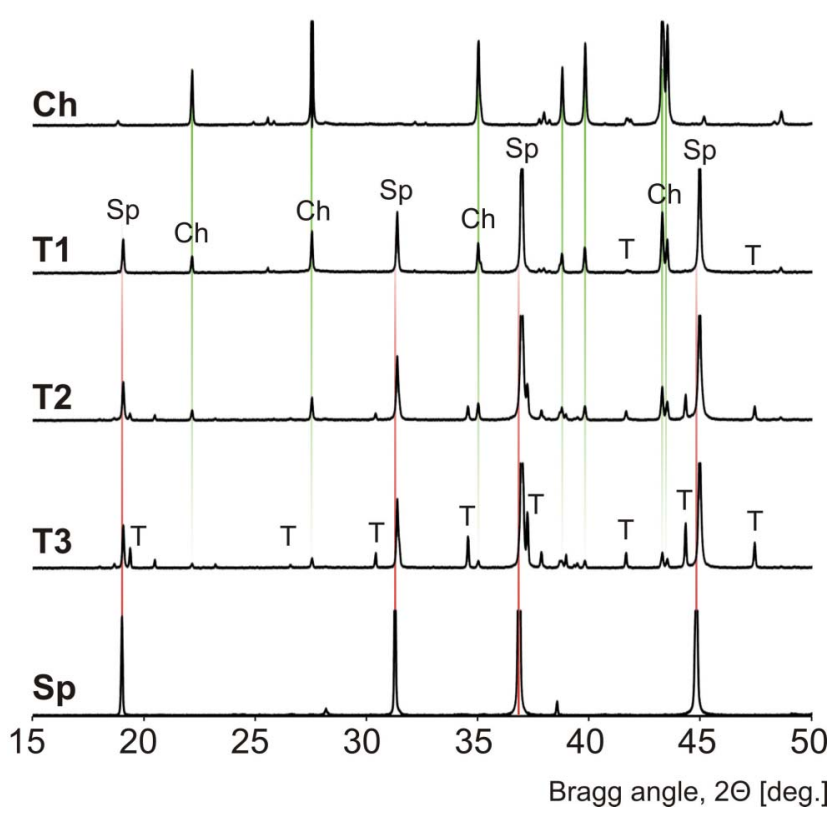

Fig. 1 XRD patterns of the samples with compositions listed in Table 1. Green lines indicate positions of major chrysoberyl (Ch) reflections, whereas red lines indicate the positions of major spinel (Sp) reflections. Note the shift of Sp reflections in T1-T3 compositions to higher Bragg angles. 
$\mathrm{Sp}$ ), only the peaks corresponding to the spinel phase are present. Similarly, in the sample, where the $\mathrm{Al}_{2} \mathrm{O}_{3}$ and $\mathrm{BeO}$ were mixed in the ratio for $\mathrm{BeAl}_{2} \mathrm{O}_{4}$ (sample $\mathrm{Ch}$ ), the final product shows only the peaks corresponding to chrysoberyl. In both samples, no peaks of the starting oxides were detected indicating that in the presence of $\mathrm{PbF}_{2}$ flux the oxides completely reacted into the two targeted compounds under given sintering conditions.

On the other hand, when $\mathrm{MgO}, \mathrm{Al}_{2} \mathrm{O}_{3}$ and $\mathrm{BeO}$ were mixed in the ratios corresponding to the intermediate polytypic taaffeite phases, as suggested in the literature (Table 1), the products did not correspond to the targeted phases, as anticipated. Under our processing conditions, only the formation of taaffeite $\mathrm{BeMg}_{3} \mathrm{Al}_{8} \mathrm{O}_{16}$ phase (T3) was observed in all three samples. The intensity of the diffraction peaks of taaffeite gradually decreases from sample $\mathrm{T} 3$ with a stoichiometric composition for the $\mathrm{BeMg}_{3} \mathrm{Al}_{8} \mathrm{O}_{16}$ phase, to the sample T1 with the composition for the $\mathrm{BeMgAl}_{4} \mathrm{O}_{8}$ phase. In addition, residual spinel and chrysoberyl peaks are observed in all three samples. While a relative intensity of the peaks corresponding to spinel phase (Sp) appears to be similar in all three samples, the relative intensity of the chrysoberyl peaks (Ch) apparently decreases form sample $\mathrm{T} 1$ to sample T3. In addition to incomplete reactions to the targeted phases, another peculiar feature can be observed in the XRD spectra of T1-T3 samples. Namely, if we take a closer look at the positions of spinel-type reflections in the T1-T3 samples we observe that they are all shifted towards larger Bragg angles if compared to the corresponding peaks in the Sp sample. The shift is not constant but gradually increases with increasing $2 \theta$ angle (see Fig. 1). This indicates that the spinel phase in T1-T3 samples has a smaller unit-cell ( $a=8.060 \AA$ ) than the regular spinel ( $a=$ $8.086 \AA$ ). The possible reason for the reduction of the unit-cell in these samples could be non-stoichiometry of the spinel phase (cation disorder, incorporation of impurities, point defects, etc.). ${ }^{6,20}$

Considering the relative peak intensities observed in the XRD spectra (see Fig. 1) of the three starting compositions (T1T3), following partial reactions can be written:

$$
\begin{gathered}
\mathrm{T} 1: 12 \mathrm{MgO}+12 \mathrm{BeO}+24 \mathrm{Al}_{2} \mathrm{O}_{3} \rightarrow \\
1 \mathrm{BeMg}_{3} \mathrm{Al}_{8} \mathrm{O}_{16}+11 \mathrm{BeAl}_{2} \mathrm{O}_{4}+9 \mathrm{MgAl}_{2} \mathrm{O}_{4} \\
\mathrm{~T} 2: 16 \mathrm{MgO}+8 \mathrm{BeO}+24 \mathrm{Al}_{2} \mathrm{O}_{3} \rightarrow \\
2 \mathrm{BeMg}{ }_{3} \mathrm{Al}_{8} \mathrm{O}_{16}+6 \mathrm{BeAl}_{2} \mathrm{O}_{4}+10 \mathrm{MgAl}_{2} \mathrm{O}_{4} \\
\mathrm{~T} 3: 18 \mathrm{MgO}+6 \mathrm{BeO}+24 \mathrm{Al}_{2} \mathrm{O}_{3} \rightarrow \\
3 \mathrm{BeMg}_{3} \mathrm{Al}_{8} \mathrm{O}_{16}+3 \mathrm{BeAl}_{2} \mathrm{O}_{4}+9 \mathrm{MgAl}_{2} \mathrm{O}_{4}
\end{gathered}
$$

The presence of residual spinel and chrysoberyl phases in the samples indicates that the reaction between the starting oxides is diffusion controlled and that the sintering conditions were not optimal to allow complete reaction of starting oxides into the ternary $\mathrm{BeMg}_{3} \mathrm{Al}_{8} \mathrm{O}_{16}$ phase. This suggests that under our synthesis conditions binary phases spinel and chrysoberyl are formed preferentially, whereas the ternary taaffeite phase necessitates at least one of the binary phases for its formation. Possible reasons for slow kinetics are in the fast heating rate, long diffusion paths due to high amount of added liquid
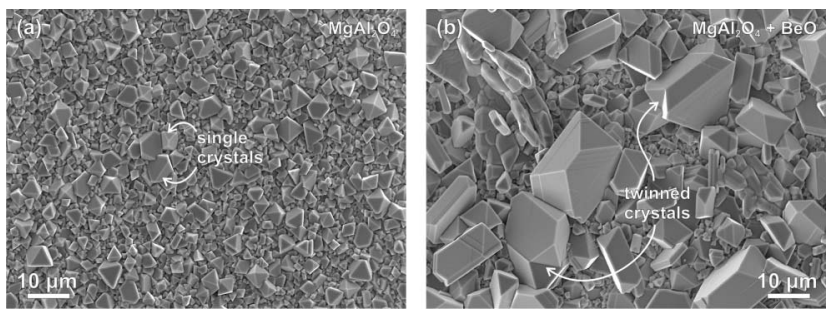

Fig. 2 The influence of twinning on crystal growth in spinel-based ceramics. (a) Undoped spinel (Sp) sample composed of small octahedral crystals. (b) Spinel doped with $10 \mathrm{~mol} \% \mathrm{BeO}$. The microstructure is characterized by large twinned crystals, up to 5-times larger than the simple octahedral crystals in the undoped sample. Twinned crystals are displaying distinctive re-entrant angles. Two typical twins are marked by arrows. Magnification of the SEM images is identical for easier comparison of the crystal sizes.

phase, and rapid evaporation of the flux, as no residual peaks were observed in the XRD patterns. EDS analyses of taaffeite samples have confirmed our XRD results: no other intermediate compounds could be confirmed except for the $\mathrm{BeMg}_{3} \mathrm{Al}_{8} \mathrm{O}_{16}$ phase, occurring in the form of thin lamellar grains in the matrix of fine-grained spinel and chrysoberyl. As beryllium cannot be detected by EDS analysis the $\mathrm{Mg}$ : $\mathrm{Al}$ ratio was measured in order to identify the taaffeite compositions. The amount of $\mathrm{BeMg}_{3} \mathrm{Al}_{8} \mathrm{O}_{16}$ phase was the largest in the $\mathrm{T} 3$ sample and the lowest in the T1 sample, as indicated by XRD analysis.

\section{Twinning in $\mathrm{MgAl}_{2} \mathrm{O}_{4}$ with the addition of $\mathrm{BeO}$}

Surfaces of sintered pellets of an undoped spinel sample (Sp) and that with the addition of $\mathrm{BeO}$ are shown in Fig. 2 . Undoped $\mathrm{MgAl}_{2} \mathrm{O}_{4}$ sample is composed of uniform, up to $\sim 5$ $\mu \mathrm{m}$ large grains with simple isometric octahedral morphology (Fig. 2a). Because of relatively large amounts of $\mathrm{PbF}_{2}$ flux used to enhance crystal growth and expose crystal morphology, the samples with lower additions (0.1 and $1.0 \mathrm{~mol} \%)$ of BeO did not show twinning due to dissolution in $\mathrm{PbF}_{2}$. For this reason, the addition of $\mathrm{BeO}$ was increased to $10 \mathrm{~mol} \%$ and the twins appeared in abundance (Fig. 2b). As opposed to the undoped $\mathrm{MgAl}_{2} \mathrm{O}_{4}$ sample, most of the spinel grains here are twinned and exaggeratedly grown. The diameters of twinned crystals easily exceed $\sim 20 \mu \mathrm{m}$.

As anticipated from the atomistic study of naturally twinned spinel crystals,${ }^{4}$ the presence of Be indeed triggers twinning in $\mathrm{MgAl}_{2} \mathrm{O}_{4}$. A detailed inspection of the samples revealed that $\{111\}$ twins form in different growth stages. Non-equilibrium growth conditions and high amounts of the liquid phase greatly contributed to inhomogeneous distribution of $\mathrm{BeO}$ in the microstructure. Knowing that one monolayer of $\mathrm{Be}^{2+}$-ions is needed to trigger a single (111) twin boundary in spinel, ${ }^{4}$ the concentration of $\mathrm{BeO}$ can in principle be calculated for each point in the microstructure. The local concentration of $\mathrm{BeO}$ that is available for twin formation is proportional to the number of twin boundaries per unit volume of spinel. Using a simplified microstructural model composed of cubic grains, ${ }^{21}$ we would need, e.g. only $\sim 6 \mathrm{ppm}$ of $\mathrm{BeO}$ for the growth of 10 $\mu \mathrm{m}$ large spinel crystals, each containing a single (111) twin boundary. If the number of twin boundaries per grain is larger, 

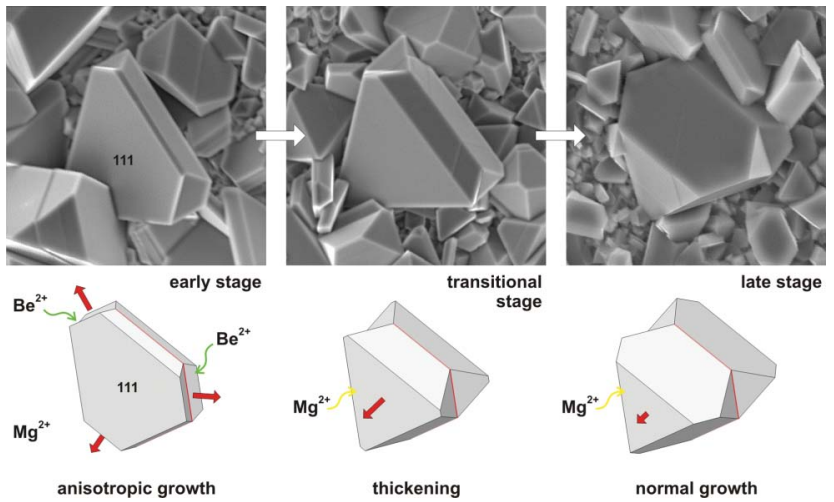

stage

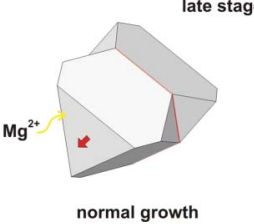

Fig. 3 Development of (111) twin of spinel. In the nucleation stage the presence of $\mathrm{Be}^{2+}$ ions triggers the formation of (111) twin boundary. In this early stage the crystal grows preferentially along the twin boundary (red line) which is reflected in an unusual tabular morphology of such a composite crystal. As soon as the supply of $\mathrm{BeO}$ is interrupted, the crystal starts to thicken. In the transitional stage the crystals develop a characteristic twin morphology. This is followed by normal growth of the two crystal domains if $\mathrm{BeO}$ does not re-enter the growth process. In the micrographs the size of central twinned crystals is $\sim 20 \mu \mathrm{m}$.

the concentration of $\mathrm{BeO}$ is proportionally higher. Based on our observations twin boundaries nucleate on any of the available $\{111\}$ surfaces of spinel crystals. Furthermore, depending on local availability of $\mathrm{BeO}$, nucleation of a twin boundary takes place at any time during crystal growth, forming complex twin combinations.

Let us first take a look at the formation and growth of a simple contact (111) twin of spinel. According to Daneu et al. ${ }^{4}$ $\mathrm{Be}^{2+}$ ions can occupy the tetrahedral interstices in mixed $\{222\}$ layers of the spinel structure and thus form a local hcp stacking fault, which is the basic element of the twin boundary. As soon as this stacking is formed the twin boundary starts to efficiently accommodate all free $\mathrm{Be}^{2+}$ ions from the surroundings. If the concentration of $\mathrm{Be}^{2+}$ is high enough, twin boundaries will be formed on more free octahedral faces, however if its concentration is relatively low, all $\mathrm{Be}^{2+}$ ions will be used for the growth of an already nucleated twin boundary. This is confirmed by extreme anisotropic growth along the twin boundary in the initial stages of growth. Such crystals display an unusual tabular morphology. When the supply of $\mathrm{BeO}$ is locally discontinued the twin boundary stops forming and the crystal starts to thicken. Eventually this process leads to the formation of almost two perfect octahedra adjoined by a common octahedral face; the original twin boundary. The described growth stages are illustrated in Fig. 3 .

Twin boundaries can simultaneously form on several octahedral faces and complex twin combinations can develop. Some of the observed complex twins are illustrated in Fig. 4. If we assume that the twin boundary nucleates at a fixed rate under selected sintering temperature, the rate of $\mathrm{Be}^{2+}$ diffusion to the nucleation sites is the controlling mechanism for the twin formation. In such a case, the growth of an existing twin boundary is sustained. However, if the concentration of $\mathrm{Be}^{2+}$ ions is larger than the nucleation rate of the
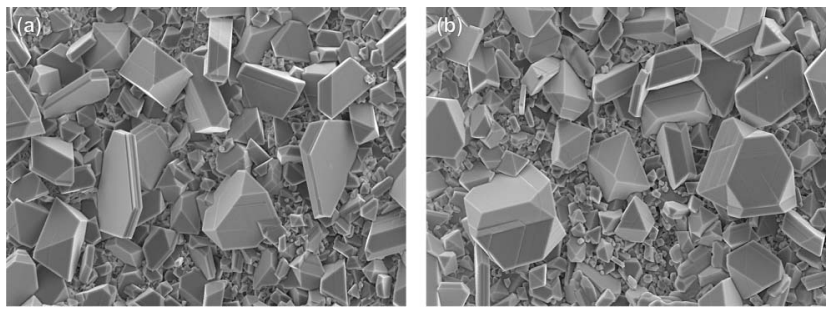

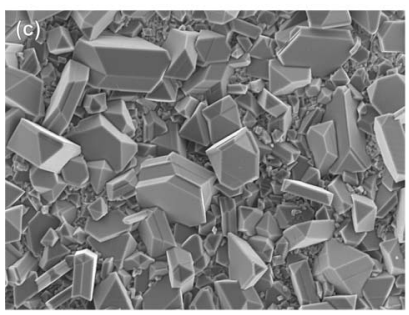

(e)

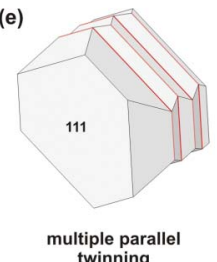

twinning (f)

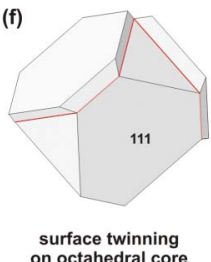

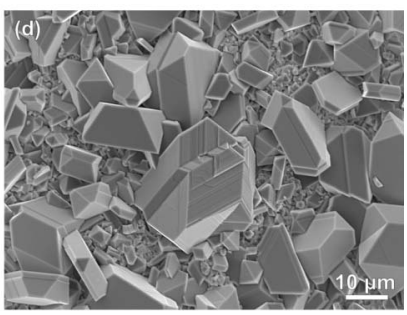

(g)
Fig. 4 Complex $\{111\}$ twinning of spinel crystals. (a) Composite lamellar twins produced by many parallel twinning events in the early growth stage. SEM micrograph shows two such twins in the left side of the image and one on the right. (b) Cyclic twin composed of three spinel crystals (right). Such a twin is formed by simultaneous nucleation of two neighboring $\{111\}$ twin boundaries on the same primary octahedral crystal in an early growth stage. In this case anisotropic growth took place along two directions, resulting in a rapid growth of the central crystal. On the left is a simple contact (111) twin in the late growth stage with distinct growth ledges. (c) Multiple parallel twin with larger distance between the twin boundaries (centre left) and a cyclic twin in its early growth stage (centre right). (d) Complex cyclic-parallel twin, similar to the one used for TEM analysis in Fig. 5. For clarity some twins are illustrated below, (e) multiple parallel twin ( $f$ ) cyclic twin in an early growth stage and (g) cyclic twin in the transitional growth stage. The illustrations are briefly matching the crystals shown in (c) and (b).

twin structure, a surplus of $\mathrm{Be}^{2+}$ ions will be available for the formation of a new twin boundary in close vicinity of the preexisting. If, for example, in the abundance of $\mathrm{BeO}$, new twin boundaries are nucleated on the large octahedral faces, during the early stage of growth of a simple contact (111) twin, multiple parallel twins can be formed (Fig. 4a). A distance between the parallel twin boundaries depends on the duration of the crystal thickening phase before the new twin boundary is formed (Fig. 4c and 4e). On the other hand, if in the early stage of growth twin boundaries are nucleated on different $\{111\}$ planes of the primary octahedral crystal, cyclic twins can be formed (Fig. 4b and 4c). Even when the twin boundaries are formed on neighboring octahedral faces, as in the case of cyclic twins, such a crystal obeys the same principles as the simple contact twin; it grows exaggeratedly along both twin boundaries, resulting in large central crystal covered with thin platelet crystal domains on both sides of the twin boundaries (Fig. 4c and 4f). In the late stages of growth the platelet domains covering the central crystal thicken (Fig. $4 \mathrm{~b}$ and $4 \mathrm{~g}$ ). 

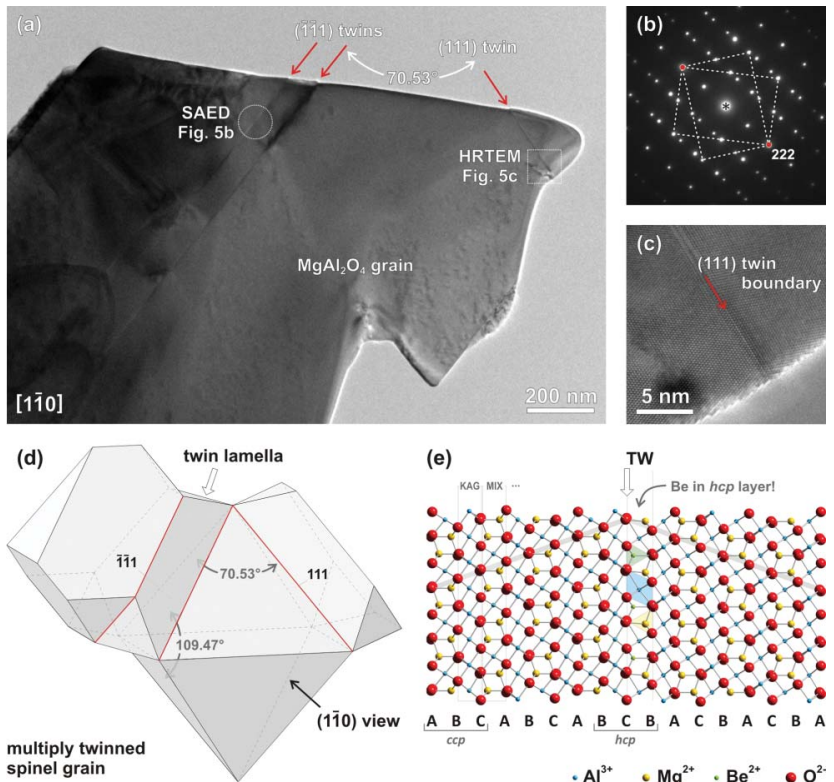

(e)

Tw

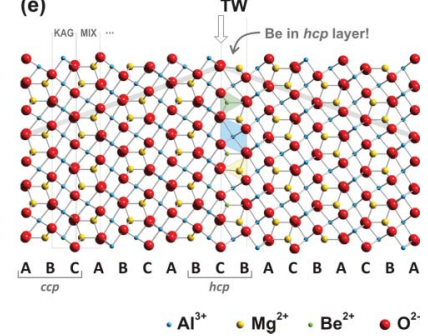

Fig. 5 Twinning of spinel in $\mathrm{MgO}-\mathrm{Al}_{2} \mathrm{O}_{3}$ ceramics doped with $10 \mathrm{~mol} \% \mathrm{BeO}$. (a) TEM image of a $\mathrm{MgAl}_{2} \mathrm{O}_{4}$ spinel grain viewed along the [1 10 ] zone axis. The grain contains multiple twin boundaries extending along different sets of $\{111\}$ planes. (b) SAED pattern recorded across the twin boundary marked in (a). (c) HRTEM image of (111) twin boundary from the thin part of $\mathrm{MgAl}_{2} \mathrm{O}_{4}$ spinel grain outlined in (a). (d) Illustration of multiply twinned spinel grain as shown in Fig. $4 \mathrm{~d}$ and $5 \mathrm{a}$. According to the geometry of an ideal octahedron, twin boundaries can enclose angles of $70.53^{\circ}$ (acute), $109.47^{\circ}$ (obtuse) and $180^{\circ}$ (parallel). (e) Structural model of (111) twin boundary with $\mathrm{Be}^{2+}$ occupying interfacial tetrahedral sites, according to Daneu et al. ${ }^{4}$ The sequence of kagome (KAG; $3 / 4$ octahedral) and mixed (MIX; $1 / 4$ tetrahedral type-I, $1 / 4$ octahedral and $1 / 4$ tetrahedral type-II) layers is uninterrupted across the twin boundary, whereas the cubic stacking sequence of close-packed O-layers (ccp) is locally hexagonal (hcp). The grey line in the background of the model indicates the faulted stacking in the oxygen sub-lattice.

Similar multiple twins have been observed in natural spinel crystals from Burma and Sri Lanka. ${ }^{4,22,23}$ Any of these basic types of twins can be further decorated by additional twin boundaries to form more complex twin clusters (see Fig. 4d and $5 \mathrm{a}$ ) in the later stages of growth, as long as $\mathrm{BeO}$ is available for their nucleation.

The spinel sample with the addition of $10 \mathrm{~mol} \% \mathrm{BeO}$ was further inspected by TEM. We found that also in the interior of the pellet every spinel grain contains at least one (111) twin boundary. According to EDS analysis, the chemical composition of spinel grains corresponds to normal $\mathrm{MgAl}_{2} \mathrm{O}_{4}$ with the $\mathrm{Mg}$ : Al ratio of $1.00( \pm 0.012): 2.00( \pm 0.022)$. Quite frequent are situations, where a single spinel grain contains multiple twin boundaries, among which most common are pairs of parallel, obtuse (the incidence angle of $109.47^{\circ}$ ) and acute (incidence angle of $70.53^{\circ}$ ) combinations of twin boundaries. These angles correspond to the angles enclosed by different $\{111\}$ faces of an octahedron, if it is viewed along the [110] projection. One of such complex twin clusters of spinel is analyzed in Fig. 5. The width of the twin lamellae in this sample varies from 50-200 $\mathrm{nm}$. As discussed above, this width corresponds to the frequency of twinning events during growth. Twin boundaries are atomically sharp and only occasionally they make steps away from the $\{111\}$ planes. Selected area electron diffraction (SAED) recorded on one such boundary viewed along the [110] axis (Fig. 5a), shows a twin pattern with (111) plane as a mirror plane (Fig. 5b). An illustration of a multiply twinned grain of spinel, shown in Fig. 5d, demonstrating the complexity of twinning in BeOdoped $\mathrm{MgAl}_{2} \mathrm{O}_{4}$ ceramics. The SEM image of such a twin cluster, as analyzed here, is shown in Fig. 4d. According to the structural study of (111) twin boundaries in spinel by Daneu et $a .^{4}$ the twin operation is $180^{\circ}$ rotation about the [111]-axis with (111) plane as the twin composition plane. Following this operation, cubic close-packed (ccp) O-sublattice of spinel locally suffers a hexagonal (hcp) stacking fault. This hep stacking is the structural origin of twinning. The authors suggested that hcp stacking might be triggered by incorporation of $\mathrm{Be}^{2+}$ of the interfacial tetrahedral sites (Fig. 5e), however, by studying natural twins of spinel they were not able to provide a direct experimental evidence that $\mathrm{BeO}$ in fact causes the twinning. On the other hand, Tabata and Ishii ${ }^{19}$ succeeded to synthesize twins of spinel by the addition of chrysoberyl, however their experiment was inconclusive whether twinning in natural spinels is caused by $\mathrm{Be}^{2+}$ or $\mathrm{Si}^{4+}$. In our study we provided a direct evidence that twinning in spinel is chemically induced and is not a consequence of an accidental attachment of crystals, as commonly anticipated. $^{22,23}$

As demonstrated in other ceramic materials, the formation of chemically induced planar faults strongly influences the microstructure development. ${ }^{2,3}$ In a similar way, the presence of $\mathrm{Be}^{2+}$ during growth causes twinning of spinel crystals. When the concentration of $\mathrm{BeO}$ in the surroundings is low it can only form isolated hcp sequences (twin boundaries) during the growth of spinel. Each such faulted sequence can be sustained in growth as long as the dopant (BeO) necessary for its formation is available, and as long as thermodynamic conditions allow the formation of hcp stacking. The formation of this Be-rich 2D phase introduces a high internal crystal anisotropy within the spinel structure. In a race to overgrow the internal fault, twin domains start to grow exaggeratedly along the twin plane. Because of the (111) twin boundary these, otherwise cubic crystals, develop an unusual plate-like morphology due to rapid growth along the twin composition plane. As a result, extremely thin, tabular crystals are developed (see Fig. 3a). Such tabular and other complex morphologies have been commonly observed in natural twins of spinel. ${ }^{4,23}$ During sintering, spinel crystals in undoped $\mathrm{MgO}-\mathrm{Al}_{2} \mathrm{O}_{3}$ ceramics develop as isometric grains (see Fig. 2a), resulting in intrinsically brittle ceramic product. One of the methods for toughening of ceramics is the addition of platelike particles or whiskers into a fine-grained polycrystalline matrix in order to dissipate energy by deflecting cracks, and thereby increasing material strength and toughness. In this view plate-like growth of cubic spinel crystals may be an interesting phenomenon worth investigating in view of the material's microstructural and physical properties. ${ }^{1}$ 


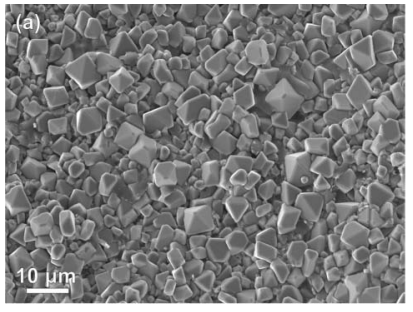

(c)

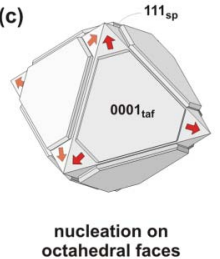

(d)

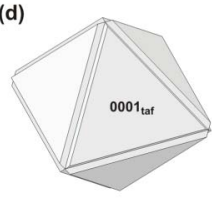

epitaxial overgrowth

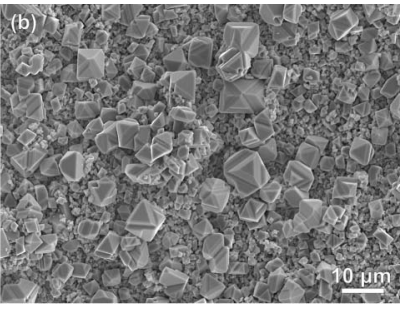

(e)

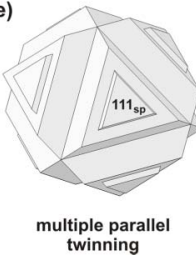

Fig. 6 Epitaxial overgrowth of taaffeite on $\{111\}$ faces of spinel. (a) Coherent overgrowth of $\mathrm{BeMg}_{3} \mathrm{Al}_{8} \mathrm{O}_{16}$ over the primary octahedral spinel crystals. The epitaxial layers can be recognized by unusual $\{100\}$ and $\{110\}$ faces on octahedrons that are not typical for spinel. (b) Lamellar epitaxial overgrowth of disordered $\mathrm{BeMg}_{3} \mathrm{Al}_{8} \mathrm{O}_{16}$ intercalated with a frequently twinned spinel phase. Three stages of epitaxial overgrowth: (c) the formation of twin boundary or continuous taaffeite layers on all 8 octahedral faces of spinel, (d) complete overgrowth of octahedral faces, and (e) multiple parallel twinning of spinel with topotaxial taaffeite layers.

\section{Epitaxial relationship between spinel and taaffeite}

Among complex twinned spinel crystals at the centre of the sample with $10 \mathrm{~mol} \%$ addition of $\mathrm{BeO}$ we also found thin lamellar grains of taaffeite. The presence of a minor $\mathrm{BeMg}_{3} \mathrm{Al}_{8} \mathrm{O}_{16}$ taaffeite phase was confirmed by XRD. To investigate the mode of polytype formation in the $\mathrm{MgO}-$ $\mathrm{Al}_{2} \mathrm{O}_{3}-\mathrm{BeO}$ system, we used the T3 sample with the highest amount of $\mathrm{BeMg}_{3} \mathrm{Al}_{8} \mathrm{O}_{16}$ phase, according to our XRD measurements (Fig. 1). In order to produce a taaffeite lamella the concentration of $\mathrm{BeO}$ must exceed $12.5 \mathrm{~mol} \%$. While EDS analysis of twinned spinel grains shows normal $\mathrm{Mg}: \mathrm{Al}=1: 2$ ratio, in taaffeite samples this ratio decreases due to the presence of Be in the structure. Any depletion of $\mathrm{Mg}$ indirectly shows the amount of Be present in the structure. In this sample, the average $\mathrm{Mg}: \mathrm{Al}$ ratio, measured on 17 different locations, either on taaffeite or spinel grains, was 0.76 $( \pm 0.014): 2.00( \pm 0.026)$, indicating that beryllium is incorporated into the spinel structure before its actual transformation to $\mathrm{BeMg}_{3} \mathrm{Al}_{8} \mathrm{O}_{16}$ taaffeite. These results are consistent with the observed reduction of the spinel unit-cell in our XRD data of T1-T3 samples. Fig. 6 shows the surface of the pellet at two different locations. The outer rim of the pellet (Fig. 6a) is dominated by small octahedral crystals epitaxially overgrown with a thin layer of taaffeite, as confirmed by EDS analysis. Their size barely exceeds that of an undoped spinel sample (see Fig. 2a). The crystals have an octahedral form, similar to that of a pure spinel. The unusual cube $\{100\}$ and rhombic dodecahedral $\{110\}$ faces truncating the corners and edges of octahedrons result from taaffeite overgrowth. At the centre of the pellet, however, the crystals are slightly larger $(\sim 10 \mu \mathrm{m})$ and display an uncommon stepped topography of octahedral faces (Fig. 6b). This unusual growth could originate from

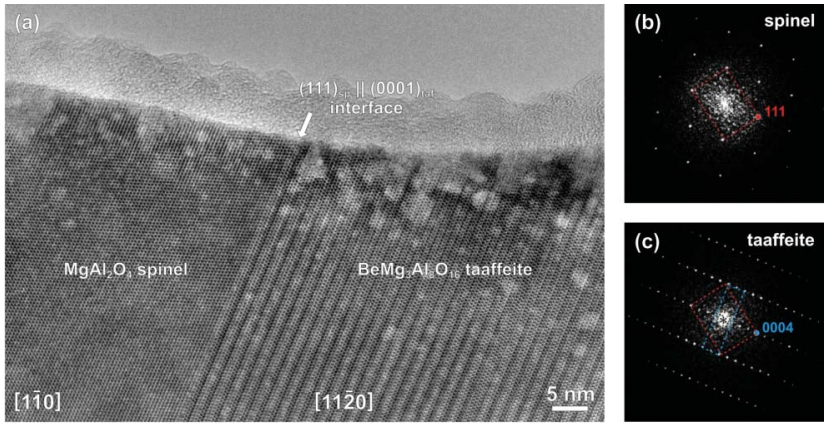

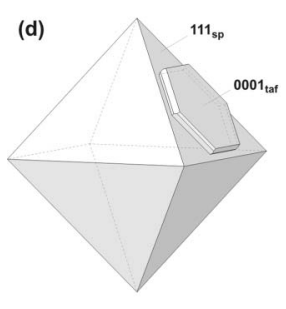

epitaxial taaffeite on spinel (e)

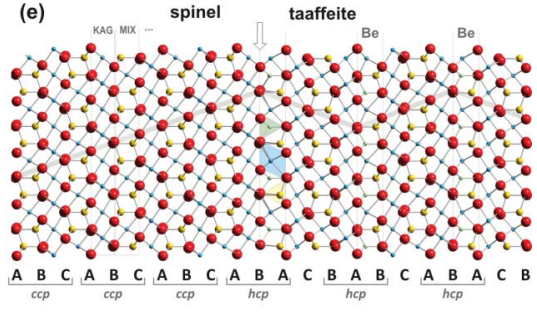

Fig. 7 Polytypic BeMg ${ }_{3} \mathrm{Al}_{8} \mathrm{O}_{16}$ phase (taaffeite) epitaxial on spinel in T3 sample. (a) HRTEM image of spinel (left) viewed along the [1 $1 \overline{0}$ ] zone axis with epitaxial $\mathrm{BeMg}_{3} \mathrm{Al}_{8} \mathrm{O}_{16}$ phase (right). The interface is atomically sharp and contains no dislocations, whereas taaffeite is almost perfectly periodic with occasional (0001) stacking faults; FFT transforms from (b) spinel and (c) taaffeite indicates high structural coherency between the two phases. (d) Illustration of octahedral spinel crystal with epitaxial taaffeite. (e) Structural model of the spinel-taaffeite interface reconstructed based on the observed stacking on HRTEM image

(Fig. 4a). The local structure across the hcp closely resembles that of the Be-rich twin boundary in spinel (Fig. 3e). $\mathrm{BeMg}_{3} \mathrm{Al}_{8} \mathrm{O}_{16}$ used in our model is after Moor et al. ${ }^{15}$

multiple parallel twinning on every face of the primary octahedral crystal of spinel. Exaggerated growth along all 8 octahedral planes is soon self-confined and as a result such crystals cannot exhibit anisotropy in any direction. The only directions available for growth are those normal to the twin planes, i.e. primary octahedral faces. Because of the high concentration of $\mathrm{BeO}$ in the sample, every few layers of spinel that are grown on the surfaces another twin boundary is formed and occasionally, more or less ordered layers of taaffeite are deposited topotaxially. Epitaxial overgrowth on primary spinel crystals is illustrated in Fig. 6c-6e.

The sample was further studied by TEM to reveal the existence of coherent intergrowths of spinel and taaffeite phases. The structural analysis of epitaxial overgrowth is illustrated in Fig. 7. The widths of polytype lamellae ranges from a few layers up to several hundreds of nanometers. The observed crystallographic relation between $\mathrm{MgAl}_{2} \mathrm{O}_{4}$ (spinel) and $\mathrm{BeMg}_{3} \mathrm{Al}_{8} \mathrm{O}_{16}$ (taaffeite) obeys the following orientation relationship: $[1 \overline{1} 0] \cdot\{111\}_{\text {sp }} \|[11 \overline{2} 0] \cdot\{0001\}_{\text {taf }}$ (Fig. 4a and illustration in Fig. 7d). The periodicity of taaffeite in our T3 sample corresponds to the reported $\mathrm{BeMg}_{3} \mathrm{Al}_{8} \mathrm{O}_{16}$ phase. ${ }^{15}$ Fourier transforms of lattice images from spinel (Fig. 7b) and taaffeite (Fig. 7c) reveal a high structural coherency, which is the main prerequisite for a complete topotaxial intergrowth of the two phases. If we take a look at the hypothetical structural model of the spinel-taaffeite epitaxy (Fig. 7e), based on the observed 
stacking from experimental HRTEM image (Fig. 7a), it becomes evident that both structures share a common O-sublattice (ccp), with intermittent hexagonal (hcp) sequences, structurally identical to the local stacking observed on the (111) twin boundaries in spinel (Fig. 5e). Hexagonal stacking of the O-sublattice due to incorporation of Be was already anticipated in the first crystallographic characterization of taaffeite by Anderson et al. ${ }^{9}$ The actual similarity between the (111) twin boundary structure and hcp layers of the $\mathrm{BeMg}_{3} \mathrm{Al}_{8} \mathrm{O}_{16}$ (Moor et al. $)^{15}$ is astonishing: (i) each hcp fault is accomplished by $180^{\circ}$ rotation about the [111] axis, on any structural site in the O-sublattice, ${ }^{4}$ by this operation the second set of $(\overline{2} \overline{2} 2)$ kagome layers are shifted for the height of one octahedral layer parallel to the (111) twin boundary by $R=$ [22̄] , and (ii) $\mathrm{Be}^{2+}$ ions in mixed layers exclusively occupy the interfacial tetrahedral sites, adjacent to the faulted (hcp) stacking in the O-sublattice, and never those adjacent to normal (ccp) stacking, (iii) whereas $\mathrm{Al}^{3+}$ and $\mathrm{Mg}^{2+}$ ions occupy identical sites as in the spinel structure. Other taaffeite-type structures $^{12-14}$ do not obey these crystallographic principles and their structures should probably be reconsidered.

Epitaxial growth of taaffeite phase on spinel in a similar structural pattern as observed on (111) twin boundaries in spinel additionally confirms our premise that chemically induced twinning is nothing but a preparatory stage of polytypic phase formation. ${ }^{2}$ Except for the $\mathrm{BeMg}_{3} \mathrm{Al}_{8} \mathrm{O}_{16}$ phase we have not confirmed the presence of any other polytypes reported to exist in the $\mathrm{MgO}-\mathrm{Al}_{2} \mathrm{O}_{3}-\mathrm{BeO}$ system. ${ }^{16}$ Faulted stacking in an otherwise perfect $\mathrm{BeMg}_{3} \mathrm{Al}_{8} \mathrm{O}_{16}$ structure was observed occasionally. This is mainly due to the specific processing conditions and other polytypes may be stable at other temperatures. Because of their relative rarity natural taaffeites are today exclusively used as precious gemstones. ${ }^{18}$ While both end-members, spinel and chrysoberyl, are known to have a range of applications due to their excellent optical properties, taaffeite-based ceramics has not yet been utilized for technological purposes.

\section{Conclusions}

We have demonstrated that $\mathrm{MgAl}_{2} \mathrm{O}_{4}$ spinel, $\mathrm{BeAl}_{2} \mathrm{O}_{4}$ chrysoberyl and the intermediate $\mathrm{BeMg}_{3} \mathrm{Al}_{8} \mathrm{O}_{16}$ taaffeite phase can be successfully synthesized at $1200{ }^{\circ} \mathrm{C}$ with the addition of $\mathrm{PbF}_{2}$ flux. Phase composition analyses indicated that under the applied processing conditions, the only stable ternary phase is the $\mathrm{BeMg}_{3} \mathrm{Al}_{8} \mathrm{O}_{16}$ taaffeite, whereas the other compounds reported in the literature were not found in our samples. The addition of already small amounts of $\mathrm{BeO}$ to the $\mathrm{MgO}-$ $\mathrm{Al}_{2} \mathrm{O}_{3}$ ceramic system has a dramatic effect on $\mathrm{MgAl}_{2} \mathrm{O}_{4}$ grain growth. It results in the formation of plate-like and complexshaped spinel grains, which are a consequence of chemically induced twinning of $\mathrm{MgAl}_{2} \mathrm{O}_{4}$. With an increasing addition of $\mathrm{BeO}$ we observe epitaxial growth of $\mathrm{BeMg}_{3} \mathrm{Al}_{8} \mathrm{O}_{16}$ on the primary grains of $\mathrm{MgAl}_{2} \mathrm{O}_{4}$. In our experiments we could confirm that $\{111\}$ twinning in spinel is a direct consequence of $\mathrm{BeO}$ addition; low concentrations of $\mathrm{BeO}$ lead to simple contact twinning and bimodal grain size distribution, whereas with higher concentrations of $\mathrm{BeO}$ more complex twins and grains of polytypic $\mathrm{BeMg}_{3} \mathrm{Al}_{8} \mathrm{O}_{16}$ taaffeite phase start to form. A successful attempt to induce twinning in $\mathrm{MgAl}_{2} \mathrm{O}_{4}$ by the addition of $\mathrm{BeO}$ confirms the hypothesis that twinning is not caused by accidental coalescence of crystals during growth, but is induced chemically and can be understood as a preparatory stage of polytype phase formation in the $\mathrm{MgO}-$ $\mathrm{Al}_{2} \mathrm{O}_{3}-\mathrm{BeO}$ system.

\section{Acknowledgements}

Ms. M. Gec is gratefully acknowledged for her technical assistance in preparation of TEM samples. The present work is a part of the $\mathrm{PhD}$ thesis of S. Drev financed by the Slovenian Research Agency under the contract No. PR-04365. This research was performed within the frame of the National project No. J1-4167: "Twinning, epitaxy and phase transformations in minerals".

\section{References}

1 I. Reimanis and H. J. Kleebe, A review on the sintering and microstructure development of transparent spinel $\left(\mathrm{MgAl}_{2} \mathrm{O}_{4}\right)$, J. Am. Ceram. Soc., 2009, 92, 1472-1480.

2 A. Rečnik, M. Čeh and D. Kolar, Polytype induced exaggerated grain growth in ceramics, J. Eur. Ceram. Soc., 2001, 21, 2117-2121.

3 A. Rečnik, S. Bernik and N. Daneu, Microstructural engineering of ZnO-based varistor ceramics, J. Mater. Sci., 2011, 47, 1655-1668.

4 N. Daneu, A. Rečnik, T. Yamazaki and T. Dolenec, Structure and chemistry of (111) twin boundaries in $\mathrm{MgAl}_{2} \mathrm{O}_{4}$ spinel crystals from Mogok, Phys. Chem. Miner., 2007, 34, 233-247.

5 J. Hornstra, Dislocations, stacking faults and twins in the spinel structure, J. Phys. Chem. Solids, 1960, 15, 311-323.

6 K. E. Sickafus, J. N. Wills and N. W. Grimes, Structure of spinel, J. Am. Soc., 1999, 82(12), 3279-3292.

7 E. F. Ferrell, J. H. Fang and R. E. Newnham, Refinement of the chrysoberyl structure, Am. Mineral., 1963, 48, 804-810.

8 R. F. Geller, P. J. Yavorsky, B. L. Steierman and A. S. Creamer, Studies of binary and ternary combinations of magnesia, calcia, baria, beryllia, alumina, thoria and zirconia in relation to their use as porcelains, J. Res. Natl. Bur. Stand., 1946, 36, 277-312.

9 B. W. Anderson, C. Y. Payne, G. F. Claringbull and M. H. Hey, Taaffeite, a new beryllium mineral, found as a cut gemstone, Mineral. Mag., 1951, 29, 765-772.

10 C. C. Peng and K. J. Wang, Discovery of a compact structure with 8-layers, Crystal structure analyses of taaffeite, Sci. Sin., 1963, 12, 276-278.

11 K. D. Reeve, W. J. Buykx and E. J. Ramm, The system BeO$\mathrm{Al}_{2} \mathrm{O}_{3}-\mathrm{MgO}$ at subsolidus temperatures, J. Aust. Ceram. Soc., 1969, 5, 29-32.

12 B. Chadwick, C. R. L. Friend, M. C. George and W. T. Perkins, A new occurrence of musgravite, a rare beryllium oxide, in the Caledonides of North-East Greenland, Mineral. Mag., 1993, 57, 121-129. 
$13 \mathrm{~K}$. Schmetzer, Crystal chemistry of natural Be-Mg-Al oxides: taaffeite, taprobanite, musgravite, Neues Jahrb. Mineral., Abh., 1983, 146, 15-28.

14 B. Nuber and K. Schmetzer, Crystal structure of ternary Be$\mathrm{Mg}-\mathrm{Al}$ oxides: taaffeite $\mathrm{BeMg}_{3} \mathrm{Al}_{8} \mathrm{O}_{16}$ and musgravite Be $\mathrm{Mg}_{2} \mathrm{Al}_{6} \mathrm{O}_{12}$, Neues Jahrb. Mineral., Monatsh., 1983, 9, 393-402.

15 R. Moor, F. Oberholzer and E. Gübelin, Taprobanite, a new mineral of the taaffeite-group, Schweiz. Mineral. Petrogr. Mitt., 1981, 61, 13-21.

16 T. Armbruster, Revised nomenclature of högbomite, nigerite, and taaffeite minerals, Eur. J. Mineral., 2002, 14, 389-395.

17 F. Bernhard, C. Hauzenberger and F. Walter, Pseudosinhalite, magnesiotaaffeite- $6 \mathrm{~N}^{\prime} 3 \mathrm{~S}$ and magnesiotaaffeite- $2 \mathrm{~N}^{\prime} 2 \mathrm{~S}$ as replacement product of spinel in dolomite marble from Stubenberg, Can. Mineral., 2008, 46, 1195-1205.

18 A. Abduriyim, T. Kobayashi and C. Fukuda, Identification of taaffeite and musgravite using a non-destructive single- crystal X-ray diffraction technique with an EDXRF instrument, J. Gemmol., 2008, 31, 43-54.

$19 \mathrm{H}$. Tabata and E. Ishii, Spinel twin formation in flux grown $\mathrm{MgAl}_{2} \mathrm{O}_{4}$ crystals, J. Cryst. Growth, 1980, 49, 753-756.

20 J. A. Ball, M. Pirzada, R. W. Grimes, M. O. Zacate, D. W. Price and B. P. Uberuaga, Predicting lattice parameter as a function of cation disorder in $\mathrm{MgAl}_{2} \mathrm{O}_{4}$ spinel, J. Phys.: Condens. Matter, 2005, 17, 7621-7631.

21 N. Daneu, A. Rečnik and S. Bernik, Grain growth control in $\mathrm{Sb}_{2} \mathrm{O}_{3}$-doped zinc oxide, J. Am. Ceram. Soc., 2003, 86(8), 1379-1384.

22 R. A. Fregola, N. Melone and E. Scandale, X-ray diffraction topographic study of twinning and growth of natural spinels, Eur. J. Mineral., 2005, 17, 761-768.

23 R. A. Fregola and E. Scandale, Cross-twinning in a natural spinel from Sri Lanka, Phys. Chem. Miner., 2007, 34, 529-541. 